\title{
Electrochemical skin conductance to measure sudomotor function: the importance of not misinterpreting the evidence
}

\author{
Aaron I. Vinik $^{1} \cdot$ Carolina M. Casellini $^{1} \cdot$ Henri K. Parson ${ }^{1}$ \\ Received: 20 August 2018 / Accepted: 21 August 2018 / Published online: 6 September 2018 \\ c) Springer-Verlag GmbH Germany, part of Springer Nature 2018
}

Keywords Sudoscan $\cdot$ Electrochemical skin conductance $\cdot$ Neuropathy $\cdot$ Sudomotor $\cdot$ Sweat $\cdot$ Autonomic neuropathy

Systematic reviews and big data analysis may sometimes result in erroneous interpretations. In this issue of Clinical Autonomic Research [13], Rajan and colleagues publish a review on sudomotor function measured by electrochemical skin conductance (ESC) $\left(\right.$ Sudoscan $\left.^{\circledR}\right)$. While the authors are to be commended for attempting to perform a systematic analysis on this increasingly relevant technique, they incurred in several instances of misinterpretation of evidence. Therefore, we would like to address several inaccuracies of their review, which, we believe, readers should be aware of.

First, the authors combined data from 37 individual articles and concluded that ESC was unable to distinguish between diseased and control individuals. The methodology they used, however, is not scientifically rigorous for a number of reasons: (a) it is unclear if the authors had access to raw data or just used reported means and standard deviations; (b) all disease types are combined, regardless of the purpose for measuring ESC in each population. For instance, ESC should not be used to diagnose cystic fibrosis, but this genetic disease is a proof-of-concept model, as chloride output in sweat is severely reduced; and (c) despite well-described differences in normative ranges in the ESC depending on ethnicity, populations were not analyzed separately. Rajan and colleagues note a lack of differences in ESC measurements in terms of sex and a modest decline in ESC with age. Normative ranges for ESC have been defined and published in large populations across many independent centers showing a progressive decrease with age with

Aaron I. Vinik

vinikai@evms.edu

1 Strelitz Diabetes Center for Endocrine and Metabolic Disorders and Neuroendocrine Unit, Department of Medicine, Eastern Virginia Medical School, Norfolk, VA, USA important differences in African and Asian individuals for whom the device now automatically adjusts the ESC thresholds for interpretation [15]. This prevents "data from individuals of African descent" from being "falsely reported as abnormal" as stated by the authors. Therefore, combining subjects with different disorders and different ethnicities is not a scientifically appropriate approach.

Second, Rajan and colleagues mention, "ESC values in individuals with chronic type-1 diabetes mellitus also appear to exceed those of control subjects'. However, according to published data [14], patients with type-1 diabetes mellitus with peripheral neuropathy had mean ESC of $53.5 \pm 25.1$ $\mu \mathrm{S}$ while controls and type- 1 diabetes mellitus without peripheral neuropathy had mean ESC of $77.1 \pm 14.3 \mu \mathrm{S}$. In a recently published work [1], patients with type- 1 diabetes mellitus whose peripheral neuropathy status was not reported had mean ESC of $82 \pm 8 \mu \mathrm{S}$. It is also commonly acknowledged that peripheral neuropathy is different in type- 1 diabetes mellitus and type- 2 diabetes mellitus.

Third, the statement "The coefficient of variation in subjects with diabetes was $32 \%$ " is inaccurate. Published data in patients with diabetes [9] show that the coefficient of variation of glycemia (blood glucose) was $32 \%$, whereas the coefficient of variation of ESC in the soles of the patients was 7\%. More importantly, the authors fail to cite a more recent publication specifically analyzing ESC reproducibility [2]. Repeatability and reproducibility were tested in both healthy volunteers and patients with type- 2 diabetes mellitus. For ESC in the soles, the mean repeatability standard deviation was $2.1 \mu \mathrm{S}$ (mean coefficient of variation of $2.8 \pm 1.6 \%$ ) and the mean reproducibility standard deviation was $2.3 \mu \mathrm{S}$ (mean coefficient of variation of $3.1 \pm 1.5 \%$ ) in healthy volunteers, while in patients type- 2 diabetes mellitus, the mean repeatability standard deviation was $4.3 \mu \mathrm{S}$ (mean coefficient of variation was $6.9 \pm 6.3 \%$ ) and the mean repeatability standard deviation was $4.3 \mu \mathrm{S}$ (mean coefficient 
of variation was $6.9 \pm 6.3 \%$ ), respectively. Reproducibility was also tested comparing three different devices. Interclass correlation coefficients were $0.87(0.74-0.94)$ and 0.85 $(0.71-0.93)$ in healthy volunteers and $0.95(0.89-0.98)$ and $0.88(0.74-0.96)$ in patients with type-2 diabetes mellitus for soles and palms, respectively. Although we acknowledge that Impeto Medical, the ESC device manufacturer, funded this work, and that the number of participants was low, an independent, blinded party performed all analyses. Moreover, all data can be accessed in a public repository.

Fourth, the authors also question how, following bariatric surgery, "individuals with type- 2 diabetes mellitus can regain nerve fiber function that exceeds that of the control group 24 weeks post-surgery" [4]. This is a misinterpretation of results. The study shows significant sudomotor recovery towards normal values 24 weeks after bariatric surgery in the diabetes mellitus group, but it does not exceed that of the control and pre-diabetes groups (Soles ESC at 24 weeks: diabetes mellitus: $70.1 \pm 2.8$; pre-diabetes: $71.2 \pm 2.3$; and non-diabetes: $71.3 \pm 2.3$. See [4]). Furthermore, excessive sweating during recovery following sudomotor nerve injury has been previously demonstrated by Gibbons and colleagues [8]. Similarly, Boyd and colleagues demonstrated rapid C-fiber recovery following 18-week treatment with topiramate [3]. While excessive sweating is likely only temporary and needs further investigation, dismissing the results as "biologically implausible" is shortsighted.

Fifth, the authors criticize that that the manufacturer of the ESC device funded many published studies. However, among the 25 "funded" investigators, three received only a loan of the device to test the technology and data are consistent between funded and non-funded researchers. Recent publications and presentations on the diagnosis and followup of hereditary transthyretin (TTR) amyloidosis polyneuropathy emphasize the sensitivity, reproducibility, and thus clinical utility of ESC for the detection of small fiber neuropathy in this disorder $[6,10]$. Impeto Medical did not fund this research.

Sixth, Chizmazdhev and colleagues [7] showed that the only way chloride ions can be extracted through skin at voltages below $10 \mathrm{~V}$ is via sweat ducts, providing evidence that ESC is a sweat test. In contrast, the sudomotor mechanism underlying sympathetic skin conductance still remains uncertain. ESC has been correlated with measures of small fiber neuropathy $[5,11,12]$ and the results have been consistent throughout different centers and across different countries. Importantly, a systematic review by Novak, also published in this issue of Clinical Autonomic Research, concludes that ESC has clinical utility due to its sensitivity and especially its superior reproducibility compared to other sudomotor tests currently available [12].

We acknowledge and agree with Rajan and colleagues that additional mechanistic and clinical studies are needed to better understand the in vivo physiology and target of ESC measurements. However, this should not dispel the fact that ESC measurements have promising value in clinical practice. Currently, there is a need for an objective test to evaluate neuropathy that can be extensively applied in a growing, at-risk adult population. ESC quantification is currently the simplest (less than $5 \mathrm{~min}$ ) and most accessible noninvasive test that is able to do so.

Funding None.

\section{Compliance with ethical standards}

Conflict of interest The authors have received grant support from Impeto Medical in the past.

\section{References}

1. Ang L, Jaiswal M, Callaghan B, Raffel D, Brown MB, Pop-Busui R (2017) Sudomotor dysfunction as a measure of small fiber neuropathy in type 1 diabetes. Auton Neurosc Basic Clin 205:87-92

2. Bordier L, Dolz M, Monteiro L, Nevoret ML, Calvet JH, Bauduceau B (2016) Accuracy of a rapid and non-invasive method for the assessment of small fiber neuropathy based on measurement of electrochemical skin conductances. Front Endocrinol 7:18

3. Boyd AL, Barlow PM, Pittenger GL, Simmons KF, Vinik AI (2010) Topiramate improves neurovascular function, epidermal nerve fiber morphology, and metabolism in patients with type 2 diabetes mellitus. Diabetes Metab Syndr Obes 3:431-437

4. Casellini CM, Parson HK, Hodges K, Edwards JF, Lieb DC, Wohlgemuth SD, Vinik AI (2016) Bariatric surgery restores cardiac and sudomotor autonomic c-fiber dysfunction towards normal in obese subjects with type 2 diabetes. PLoS One 11:e0154211

5. Casellini CM, Parson HK, Richardson MS, Nevoret ML, Vinik AI (2013) Sudoscan, a noninvasive tool for detecting diabetic small fiber neuropathy and autonomic dysfunction. Diabetes Technol Ther 15:948-953

6. Castro J, Miranda B, Castro I, de Carvalho M, Conceicao I (2016) The diagnostic accuracy of Sudoscan in transthyretin familial amyloid polyneuropathy. Clin Neurophysiol Off J Int Fed Clin Neurophysiol 127:2222-2227

7. Chizmadzhev YA, Indenbom AV, Kuzmin PI, Galichenko SV, Weaver JC, Potts RO (1998) Electrical properties of skin at moderate voltages: contribution of appendageal macropores. Biophys J 74:843-856

8. Gibbons CH, Wang N, Freeman R (2010) Capsaicin induces degeneration of cutaneous autonomic nerve fibers. Ann Neurol 68:888-898

9. Khalfallah K, Ayoub H, Calvet JH, Neveu X, Brunswick P, Griveau S, Lair V, Cassir M, Bedioui F (2012) Noninvasive galvanic skin sensor for early diagnosis of sudomotor dysfunction: application to diabetes. IEEE Sens J 12:456-463

10. Lefaucheur JP, Zouari HG, Gorram F, Nordine T, Damy T, PlanteBordeneuve V (2018) The value of electrochemical skin conductance measurement using Sudoscan(R) in the assessment of patients with familial amyloid polyneuropathy. Clin Neurophysiol Off J Int Fed Clin Neurophysiol 129:1565-1569

11. Novak P (2016) Electrochemical skin conductance correlates with skin nerve fiber density. Front Aging Neurosci 8:199 
12. Novak P (2017) Electrochemical skin conductance: a systematic review. Clin Auton Res. https://doi.org/10.1007/s1028 6-017-0467-x

13. Rajan S, Campagnolo M, Callaghan B, Gibbons CH (2018) Sudomotor function testing by electrochemical skin conductance: does it really measure sudomotor function? Clin Auton Res. https ://doi.org/10.1007/s10286-018-0540-0

14. Selvarajah D, Cash T, Davies J, Sankar A, Rao G, Grieg M, Pallai S, Gandhi R, Wilkinson ID, Tesfaye S (2015) SUDOSCAN: a simple, rapid, and objective method with potential for screening for diabetic peripheral neuropathy. PLoS One 10:e0138224

15. Vinik AI, Smith AG, Singleton JR, Callaghan B, Freedman BI, Tuomilehto J, Bordier L, Bauduceau B, Roche F (2016) Normative Values for electrochemical skin conductances and impact of ethnicity on quantitative assessment of sudomotor function. Diabetes Technol Ther 18:391-398 